\title{
Mitigating COVID-19 Impact on the Portuguese Population Mental Health: The Opportunity That Lies in Digital Mental Health
}

\section{OPEN ACCESS}

Edited by:

Darren C. Treadway,

Daemen College, United States

Reviewed by:

Tom Van Daele,

Thomas More University of Applied

Sciences, Belgium

Iva Georgieva,

Institute for Advanced Study

Varna, Bulgaria

*Correspondence:

Cristina Mendes-Santos

cristina.mendes.santos@liu.se

Specialty section:

This article was submitted to

Public Mental Health,

a section of the journal

Frontiers in Public Health

Received: 18 April 2020 Accepted: 04 September 2020

Published: 16 November 2020

Citation:

Mendes-Santos C, Andersson G, Weiderpass $E$ and Santana R (2020) Mitigating COVID-19 Impact on the Portuguese Population Mental Health:

The Opportunity That Lies in Digital Mental Health.

Front. Public Health 8:553345. doi: 10.3389/fpubh.2020.553345

\section{Cristina Mendes-Santos ${ }^{1,2,3 *}$, Gerhard Andersson ${ }^{4,5}$, Elisabete Weiderpass ${ }^{6}$ and Rui Santana ${ }^{2}$}

${ }^{1}$ Department of Culture and Society, Linköping University, Linköping, Sweden, ${ }^{2}$ NOVA National School of Public Health, Public Health Research Centre, Universidade NOVA de Lisboa, Lisbon, Portugal, ${ }^{3}$ Fraunhofer Center for Assistive Information and Communication Solutions, Porto, Portugal, ${ }^{4}$ Department of Behavioural Sciences and Learning, Linköping University, Linköping, Sweden, ${ }^{5}$ Psychiatry Section, Department of Clinical Neuroscience, Karolinska Institutet, Stockholm, Sweden, ${ }^{6}$ International Agency for Research on Cancer, Lyon, France

COVID-19 mitigation measures present unprecedented challenges in mental healthcare delivery, posing high risk to the mental health of at-risk populations, namely patients diagnosed with COVID-19, frontline healthcare providers, and those submitted to quarantine or isolation measures, as well as the general population. Ensuring safe and equitable access to mental healthcare by these groups entails resorting to innovative psychosocial intervention strategies, such as digital mental health. In this perspective piece, we describe the impact of COVID-19 on the Portuguese population's mental health, present an overview on initiatives developed to address the challenges currently faced by the Portuguese mental healthcare system, and discuss how the timely implementation of a comprehensive digital mental health strategy, coupling research, education, implementation, and quality assessment initiatives, might buffer COVID-19's impact on the Portuguese society.

Keywords: COVID-19, public mental health, digital mental health, internet interventions, Portugal, EU, eHealth and eMental-health

\section{INTRODUCTION}

The COVID-19 pandemic is a major public health emergency of international concern (1). As of 13th August 2020, there have been 20,439,814 confirmed cases and 744,385 deaths worldwide, with 188 countries having reported at least 1 case (2). In Portugal, the first confirmed case was diagnosed at 2nd March 2020, and since then, the spread has been fast, contaminating 53,548 people and totalizing 1,770 deaths (3). Infected patients may present a wide range of symptoms, namely fever, cough, myalgia, fatigue, sputum production, headache, hemoptysis, diarrhea, and/or dyspnea (4). Most patients seem to present with a mild disease. However, possibly as many as $20 \%$ appear to progress to severe disease, including pneumonia, respiratory failure, and, in some cases, death (5).

Due to potentially serious health outcomes of COVID-19, draconian unprecedented mitigation and suppression measures have been taken by many countries to stop the spread of the virus (6). In Portugal, the government declared an emergency state in 18th March 2020 (7), and measures, such as canceling gatherings and events, closing schools, limiting the number of people in public places (e.g., supermarkets, pharmacies, etc.), recommending social isolation, and mandating telework whenever possible have been taken to reduce contact rates in the general population and reduce 
transmission. Regarding suspect and diagnosed cases, a range of measures have been adopted, such as early identification, contact tracing and monitoring, and prophylactic isolation or mandatory quarantines (8).

The implementation of such mitigation measures combined with insufficient preparedness of health authorities, high unpredictability of the outbreak itself, and uncertainty of its social-economic impact may lead to widespread fear, anxiety, and social alarm, posing high risk to the mental health of the Portuguese population (9).

\section{COVID-19 Impact on Mental Health}

Literature on the impact of COVID-19 on mental health is still scarce. However, research on the emotional consequences of the current and previous outbreaks, such as severe acute respiratory syndrome (SARS), Middle East respiratory syndrome-related coronavirus (MERS), and Ebola virus disease indicates a high burden of mental health problems among patients, suspect cases and close contacts, frontline healthcare providers (10), those submitted to isolation and quarantine measures $(11,12)$, informal caregivers (10), the elderly (13), and the population at large (14). Prevalent mental health problems include depression, anxiety, psychological distress $(10,15)$, burnout, panic attacks, post-traumatic stress disorder (16, 17), and insomnia (12). Other adverse mental health outcomes frequently reported are fear, anger, stigmatization, low self-esteem, and lack of selfcontrol $(18,19)$. Severe conditions, such as psychotic symptoms (12) and suicidality $(20,21)$ have also been reported, although less frequently.

Epidemiological data on the prevalence of COVID-19 precipitated mental health disorders in the Portuguese population are still limited. However, previous studies reported a high burden of mental health disorders in Portugal with estimated lifetime prevalence for at least one psychiatric disorder of $42.7 \%$. When compared to other countries participating in the World Mental Health Surveys Initiative, lifetime prevalence for such disorders was only exceeded by the USA (47.4\%). All other Western European countries had lower prevalence values, namely Spain (19.4\%) and Italy (18.1\%), figures that underline the vulnerability of the Portuguese population in this domain (22).

Ongoing research $(9,23)$ promoted by Escola Nacional de Saúde Pública-Universidade Nova de Lisboa, inquiring 157,927 respondents, highlights the potential catastrophic impact the actual pandemic might have in citizens' mental health. In that study, around $83 \%$ of participants reported low mood, feeling agitated, anxious, or sad due to physical distance measures 1 week after such measures were enforced. More than $26 \%$ reported feeling this way daily or almost every day. The youngest (16-25 years of age) and female respondents were the most susceptible to confinement measures-induced distress. In addition, a positive association has been identified between the perception of risk to contract COVID-19 and the frequency of reported adverse mental health outcomes, such as feeling anxious, agitated, down, or sad (9).

Concerning healthcare workers, so far, only one study addressed mental health. In that study (24), 76.7\% of participants reported moderate to high levels of fatigue, and $68.8 \%$ of healthcare workers reported anxiety levels above normal, with physicians reporting the highest levels of anxiety.

No data are yet available on the pandemic's impact on COVID-19 Portuguese patients. However, previous research (25) acknowledges this group as an at-risk population.

\section{Populations at Risk}

Patients diagnosed with COVID-19 and suspect cases may fear the outcomes of this possibly lethal disease experiencing anxiety, emotional distress, and insomnia (10). Potential stigmatization and social exclusion may spiral into other mental health conditions, such as adjustment disorders and depression (11). Additionally, symptoms' manifestation and treatment adverse effects may aggravate premorbid mental health disorders (10). Previous research has also found increased prevalence of post-traumatic stress disorder among survivors of infectious diseases (16).

Frontline healthcare providers are submitted to enormous pressure (24) due to a high risk of infection, potential scarcity of resources, and overwork. Such work conditions, aggravated by potential discrimination and lack of contact with support networks, make this group susceptible to complex emotional reactions and mental health problems, such as stress, anxiety, depressive symptoms, insomnia, burnout, traumatic stress, denial, anger, and fear $(16,26,27)$. Reported risk factors (27-31) include being female, history of physiological chronic non-communicable diseases, family history of mental disorders, working at isolation wards, professions requiring close contact with infected patients, such as being a nurse or a medical technician, and having relatives with suspected or confirmed COVID-19. Of additional concern is the impact such conditions might have on healthcare providers' performance, potentially compromising the quality of healthcare, increasing the occurrence of medical errors and incidents, and ultimately hindering the fight against COVID-19 (31).

Special attention should also be provided to those submitted to quarantine or isolation measures. Confusion, boredom, loneliness, anxiety, anger, and guilt associated to the effects of contagion, quarantine, and stigma on family and friends are common experiences (12). Moreover, research on the psychological impact of quarantine in previous outbreaks found that being quarantined is a significant immediate and long-term risk factor to the mental health of both healthcare providers and the general population (12, 16). A study (32) targeting parents and children submitted to quarantine reported that mean post-traumatic stress scores were four times higher in children who had been quarantined than in those who were not quarantined, and almost $1 / 3$ of quarantined parents in that study fulfilled diagnosis criteria of a trauma-related mental health disorder compared to $6 \%$ of parents who were not quarantined. Another study (33) focusing on Australian horse owners submitted to quarantine due to an equine influenza outbreak reported high psychological distress in this group when compared to the general population. Concerning healthcare providers, several studies attest the deleterious and long-term impact of quarantines on mental health outcomes $(12,16,18)$. 
Having been quarantined has been identified as a predictor of depression (34) and post-traumatic stress symptoms (35) up to 3 years after the event and to be positively associated with alcohol abuse or dependency symptoms in healthcare workers (36). Another study reported quarantined staff were significantly more likely to report exhaustion, detachment from others, anxiety, irritability, insomnia, sub-optimal work performance, and absenteeism (37). Previously identified stressors comprise longer quarantine duration, infection fears, frustration, inadequate supplies, inadequate information, financial loss, and stigma (12).

Still to be assessed is the impact of COVID-19 global confinement measures on mental health. Nevertheless, recent research highlights the role social capital might have in improving quality of sleep and reducing anxiety in self-isolated individuals (14).

\section{Innovative Psychosocial Intervention Strategies}

Considering the transversal and significant impact COVID19 pandemic might have on the mental health of the general population and high-risk groups, immediate action must be taken to manage the imminent upsurge of mental health disorders associated or aggravated by coronavirus outbreak circumstances (38). Confinement measures should not enforce paralysis, and innovative psychosocial intervention strategies capable of preventing, screening, monitoring, and intervening at this level must be developed and implemented, ensuring safe and equitable access to mental healthcare (39). One such strategy is digital mental health.

Digital mental health is understood as the use of digital technologies (e.g., telephone, mobile devices, apps, videoconference and chat software, psychological assessment, support and intervention platforms, artificial intelligence, virtual reality, serious games, etc.) $(40,41)$ to support and improve mental health conditions and provide mental healthcare including screening, health promotion, prevention, early intervention, treatment, or relapse prevention (42). It encompasses a wide range of modalities that might be particularly suitable in this outbreak context, namely internet research $(43,44)$, screening and tracking tools $(45,46)$, videoconferencing counseling and psychotherapy $(45,46)$, internet interventions $(38,45,47)$, and e-learning and e-supervision (48).

Facing COVID-19 mental health-imposed challenges requires a comprehensive strategy (25), where the abovementioned modalities are interlinked and prevention/intervention programs are adjuvated by high-quality training programs and research. In the following sections, we elaborate on how such modalities could be useful during the COVID-19 crisis and report on ongoing initiatives of this kind being developed in Portugal.

\section{Internet Research}

Conducting online behavioral and mental health research associated with the COVID-19 outbreak is key to gather information on the pandemic's impact on different target populations and deliver evidence-based tailored public health interventions (49).
In Portugal, important initiatives have been launched in this domain by Escola Nacional de Saúde Pública-Universidade Nova de Lisboa (9, 23), Instituto de Saúde Pública-Universidade do Porto (50), and CESOP-Universidade Católica Portuguesa $(50,51)$ to assess the general population and frontline healthcare providers' adaptation to the outbreak and mitigation measures.

Complementarily, the Portuguese Psychologists Association created a task force supporting the expedite assessment and dissemination of research projects aiming at identifying and monitoring the population's mental health unmet support care needs and assessing the efficacy and cost-effectiveness of prevention and intervention programs or healthcare models implemented during the COVID-19 pandemic. Seventy-six online questionnaire studies are ongoing under this umbrella initiative (52) focusing on topics ranging from the use of digital technologies by psychologists during the pandemic to the characterization of COVID-19's impact on general, specific, and clinical populations.

Surprisingly, none of these studies aims at studying the effects of COVID-19 on patients diagnosed with the disease or survivors. An immediate priority is, therefore, collecting high-quality data on COVID-19's short- and long-term impact on brain function, cognition, and mental health of patients with or recovering from COVID-19 (53).

Moreover, it is vital to perform implementation research, namely pragmatic clinical trials assessing the efficacy and cost-effectiveness of different digital mental health services implemented during this pandemic (e.g., based on videoconference, apps, chatbots, etc.), to support peri and future resource allocation decisions (54). Such initiatives should take into consideration digital health equity factors and involve people from marginalized and vulnerable groups in codesign during development and implementation (55). Tackling this challenge requires integration across disciplines and institutions, and new sources of funding (53).

In this regard, the Portuguese Foundation for Science and Technology has launched specific calls to promote research on COVID-19, namely Gender Research 4 COVID-19, Research4COVID-19, and AI 4 COVID-19 (56). Nevertheless, more funding is necessary to address digital mental health research gaps in this domain and incentivize the development or adaptation of innovative tools capable of preventing, diagnosing, and mitigating the population's distress during this outbreak.

\section{Screening and Tracking Tools}

The development or adaptation of screening and tracking tools to assess and monitor mental health outcomes in high-risk populations, such as COVID-19 patients, healthcare providers, and those in quarantine, could be particularly helpful during this crisis. Screening web platforms, apps, and chatbots are highly scalable and, if coupled with artificial intelligence, have the potential of identifying mental health pressing needs and referring or providing first-aid responses to at-risk subjects (57).

In this context, chatbots are particularly interesting due to their conversational workflow and easy and rapid deployment across email, web, social media, and text (58). During COVID19 crisis and beyond, chatbots could be used to harness the 
healthcare system not only by screening and triaging citizens and healthcare providers at risk of developing mental health disorders but also by supporting in prompt education and referral.

Another interesting application of artificial intelligence in this domain is the monitorization of social networks to model pandemic trends as well as monitoring public reactions to the pandemic over time (59), facilitating psychological crisis interventions (49). Initiatives of this kind have already saved lives in China (60), and could be helpful in responding to digital native suicidal ideation since this appears to be one of the most vulnerable groups to confinement measures-induced distress (23).

Finally, leveraging all the above-mentioned dimensions, digital phenotyping is a promising strategy to passively monitor at-risk populations during crisis, such as the COVID-19 outbreak. Encompassing the passive collection and analysis of a range of behavioral data in mobile devices, including, but not limited to, spatial trajectories (via GPS), physical mobility patterns (via an accelerometer), social networks, social dynamics (via call and text logs and Bluetooth), and voice samples (via microphone) (61), digital phenotyping has the potential of increasing accuracy and bringing timeliness to the psychological assessment process (62).

To the best of our knowledge, initiatives of these kinds are not yet ongoing in Portugal, and mentioning such approaches in a country where digital mental health is at its infancy, such as Portugal, and during a crisis, may sound as pure science fiction and a waste of time. However, in technology, the future rapidly becomes the present and dissemination occurs fast, especially in times of urgency, such as the current moment. Since such approaches may be intrusive, conflict with individual freedoms, or leave vulnerable populations behind (59), their implementation must be carefully thought out and framed to guarantee that their development and implementation comply with ethical, legal, and cultural requirements and their integration in online or hybrid-healthcare models is assured, certifying that patients are adequately signaled and referred to online or physical psychiatric and psychological counseling/psychotherapy services.

\section{Tele and Videoconference Counseling and Psychotherapy}

Telephone and online psychological counseling/psychotherapy services are instrumental in providing immediate response to acute population needs and ensuring continuation of care and adequate follow-up of patients with pre-outbreak mental conditions (39).

In this regard, various helplines have been made available by hospitals, associations, and academic agencies to provide support during this crisis (63), and on the 1st of April 2020, a partnership between the Shared Services of the Portuguese Health Ministry, Calouste Gulbenkian Foundation, and the Portuguese Psychologists Association has launched a national counseling helpline to support the population (64). As of 20th July 2020, this helpline had already received 23,590 calls from healthcare providers and the general population (65), highlighting the importance of providing such first-aid resources to contain the population's distress.

Considering psychological counseling/psychotherapy services, an abrupt shift to this treatment modality has occurred after enforcement of mitigation measures, and on the 7th April 2020, the Portuguese Psychologists Association officially published Guidelines for the Provision of Psychology Services Mediated by Information and Communication Technologies (66), recommending its use during this crisis. From 4th May 2020 onwards, the Portuguese deconfinement plan started to be implemented, and clinical activity in hospitals and private practice was progressively resumed. The real number of tele and video consultations performed by psychologists and psychiatrists during and after the confinement period is not available for consultation. Yet, an analysis of available data from the Lisbon Psychiatric Hospital Centre, assumed here as a proxy, reveals a $37 \%$ decrease in telemedicine appointments in June 2020 (post-confinement) when compared to April 2020 (during confinement) (67), suggesting that a full return to the traditional face-to-face model is unlikely, and a hybrid mental healthcare model will probably emerge from this crisis. Awareness about such treatment options, patients' preferences, potential changes in providers' attitudes (68), and digital mental health research on the effectiveness and cost-effectiveness of these modalities might facilitate ongoing integration of technology (69) in the Portuguese mental healthcare system.

\section{Internet Interventions}

With millions of citizens confined or complying with social isolation recommendations worldwide (70) and, therefore, at risk not only of developing mental health conditions but also at increased risk of inactivity (71) and malnutrition (72), wider public digital health approaches may also be necessary to deliver health promotion and intervention programs (38). In this regard, internet interventions-self-help guided or unguided interventions based on established psychotherapy models operated via secure platforms or mobile apps that aim at providing synchronous or asynchronous health and mental health-related assistance $(73,74)$-may play a pivotal role in increasing the availability of self-care psychoeducational content and delivering evidence-based psychological intervention protocols (14).

Internet interventions have been found to be more effective than treatment as usual or as effective as face-to-face therapies for most COVID-19 triggered mental disorders, namely depression (75-78), generalized anxiety disorder (79-81), panic disorder $(82,83)$, insomnia $(84)$, and post-traumatic stress disorder (85). Additionally, growing evidence endorses its beneficial impact in supporting patients with somatic conditions, such as chronic pain (86), tinnitus (87), irritable bowel syndrome (88), diabetes $(89,90)$, and cancer (91-94).

Due to its high flexibility, adaptability, dissemination potential, and low delivery costs (74), internet interventions seem to be a viable approach to effectively support the general population as well as at-risk and vulnerable groups, such as chronic patients now deprived of routine healthcare (95). The equitable implementation of self-guided, guided, 
or blended approaches, possibly following a stepped care model, would facilitate psychoeducation delivery, contribute to citizens' empowerment, and ease the burden over healthcare providers, allowing them to focus on patients with severe conditions, ultimately contributing to the resilience of the healthcare system.

However, only a handful of such programs were under development or ongoing in Portugal [e.g., (96-99)] prior to the COVID-19 crisis, and, to the best of our knowledge, very few internet-delivered initiatives were developed/adapted to address COVID-19 specific constraints in the meantime (e.g., internet-delivered multimodal pre-habilitation program for confined cancer patients) (100), suggesting that well-known implementation barriers, namely clinicians' attitudes and lack of knowledge, training, and experience, persist (68). Such barriers are probably compromising the development, adaptation, and implementation of internet interventions during this crisis in Portugal.

\section{Comprehensive e-Learning and e-Supervision Initiatives}

While the COVID-19 crisis may be operating as a catalyst effect on the wide-scale acceptance and adoption of digital mental health initiatives (38), attitudinal and training barriers (68) must be expeditiously addressed in Portugal, or significant digital mental health strategies will remain unexplored, resulting in costly missed opportunities to the Portuguese mental healthcare system and its users. Overcoming such barriers implies developing and delivering adequate e-learning and esupervision programs capable of mitigating the lag between a psychologist's instruction and unfolding practice.

In this respect, initiatives under development in Portugal, such as webinars (101) and professional guidelines (66) are important but clearly insufficient. Portuguese universities and associations must take the lead and develop comprehensive (onand off-the-job) training initiatives capable of fulfilling clinicians' immediate education needs and practical concerns. Equipping the workforce with such cost-effective strategies will not only provide the necessary tools to handle the COVID-19 crisis but also enable facing the second mental health crisis that will loom in the following months, with economic recession (102).

Furthermore, digital mental health must become part of psychology courses' syllabus, and curricular and professional internships in this domain must be organized to train future clinicians in the development, refinement, and implementation of high-quality digital mental health tools and interventions.

Nevertheless, such reform is easier to imagine than to implement. Most Portuguese universities are not prepared to introduce such adjustment in their curriculums, and most faculty members hold classical stances and education, not being prepared to train future clinicians to work within a digital paradigm. Mapping and bringing together national clinicians and researchers working in the field and partnering with leading international organizations with expertise in delivering digital mental health programs might be an important contribution to achieve this goal.

\section{Paving the Road Toward a Digital Mental Healthcare Paradigm Shift}

Shifting to a digital mental healthcare paradigm entails more than willingness from clinicians, researchers, or academics. The involvement of other digital mental health ecosystem stakeholders-patients/citizens, charities and associations, companies, funders, and policymakers-is crucial to guarantee the alignment between digital mental health policy, regulatory and quality assurance frameworks, and citizens' interests.

In November 2019, an important step toward this unfolding digital revolution was taken with the publication of the National Strategic Telehealth Plan (103). Aggregating contributions from a wide range of stakeholders - members of central and regional healthcare administrations and professional nursing, medical, and pharmacists' associations - this plan aims at identifying the main challenges the country faces in this domain and proposing strategic measures to expedite the full integration of telehealth within the everyday sphere of healthcare.

Surprisingly, mental health is not mentioned in this document, and the misrepresentation of the Portuguese psychologists' association as an institutional stakeholder may be an important red flag suggesting that, once again, policymakers' attention might have focused on healthcare priorities other than mental health. It may also be the case that this omission reflects the void of initiatives ongoing in the country pre-outbreak, denouncing the embryonic stage that characterizes digital mental health in Portugal, and explaining the limited digital mental health resources applied so far to face the consequences of COVID-19 crisis. In fact, despite decades of significant evidence on the efficacy and cost-effectiveness of digital mental health initiatives worldwide (104-107), the National Mental Health Plan (108) fails to acknowledge the potential of digital mental health in contributing to promote the mental health of the Portuguese population and providing access to timely mental healthcare.

COVID-19 may have the potential of introducing disruption into the status quo. It may have the positive unintended effect of moving the Portuguese healthcare system forward by exposing its limitations and demanding a call for action. However, for this side effect to unfold, digital mental health must be recognized as a strategic opportunity not only to mitigate COVID-19's impact on the Portuguese population mental health but also to promote it beyond this pandemic. Chasing rainbows is not an option in this or the following mental health crisis. The solution lies on rethinking the National Mental Health Plan (108) at the light of the digital paradigm; aligning it with the National Strategic Telehealth Plan (103); delineating a comprehensive operational plan capable of leveraging duly funded training and implementation research initiatives; and ensuring the digital mental health road starts being paved today, with strategic implementation.

\section{CONCLUSION}

In summary, acknowledging digital mental health as a tactical opportunity and investing in a comprehensive digital mental health plan, coupling research, education, implementation, and 
quality assessment initiatives, will buffer COVID-19's impact on the Portuguese society, particularly in high-risk groups. By promoting resilience in the population and preventing the upsurge or aggravation of mental disorders, digital mental health will also strengthen the already severely burdened Portuguese mental healthcare system (22), making it capable of facing future challenges more effectively.

\section{DATA AVAILABILITY STATEMENT}

The original contributions presented in the study are included in the article/supplementary material, further inquiries can be directed to the corresponding author/s.

\section{REFERENCES}

1. WHO. Statement on the Second Meeting of the International Health Regulations (2005) Emergency Committee Regarding the Outbreak of Novel Coronavirus (2019-nCoV). Geneva: World Health Organization (2020).

2. WHO. Coronavirus Disease 2019 (COVID-19): Situation Report-206. Geneva: World Health Organization (2020).

3. DGS. COVID-19: Relatório de Situação $n^{\circ} 164$. Lisbon: Direcção Geral de Saúde (2020).

4. Huang C, Wang Y, Li X, Ren L, Zhao J, Hu Y, et al. Clinical features of patients infected with 2019 novel coronavirus in Wuhan, China. Lancet. (2020) 395:497-506. doi: 10.1016/S0140-6736(20)30183-5

5. $\mathrm{Xu} \mathrm{Z}$, Li S, Tian S, Li H, Kong LQ. Full spectrum of COVID-19 severity still being depicted. Lancet. (2020) 395:9478. doi: 10.1016/S0140-6736(20)30308-1

6. Ferguson N, Laydon D, Nedjati Gilani G, Imai N, Ainslie K, Baguelin $\mathrm{M}$, et al. Impact of Non-pharmaceutical Interventions (NPIs) to Reduce COVID19 Mortality and Healthcare Demand. London: Imperial College COVID 19 (2020).

7. Portuguesa PdR. Decreto do Presidente da República n. ${ }^{\circ} 14-\mathrm{A} / 2020$, de 18 de março. In: República Pd, editor. 14-A/2020. Lisbon: Presidência da República Portuguesa (2020). p. 13-2-4.

8. Santana R, Rocha J, Soares P, Sousa J. Os momentos das políticas de saúde no combate ao COVID-19, Barómetro COVID-19. Lisbon: Escola Nacional de Saúde Pública-Universidade Nova de Lisboa (2020).

9. Dias S, Pedro A, Abrantes A, Gama A, Moniz A, Nunes C, et al. Opinião Social: perceção individual do risco de contrair COVID-19, Barómetro COVID-19. Lisbon: Escola Nacional de Saúde Pública-Universidade NOva de Lisboa (2020).

10. Xiang YT, Yang Y, Li W, Zhang L, Zhang Q, Cheung T, et al. Timely mental health care for the 2019 novel coronavirus outbreak is urgently needed. Lancet Psychiatry. (2020) 7:228-9. doi: 10.1016/S2215-0366(20)30046-8

11. Zhang J, Wu W, Zhao X, Zhang W. Recommended psychological crisis intervention response to the 2019 novel coronavirus pneumonia outbreak in China: a model of West China Hospital. Precis Clin Med. (2020) 3:38. doi: 10.1093/pcmedi/pbaa006

12. Brooks SK, Webster RK, Smith LE, Woodland L, Wessely S, Greenberg N, et al. The psychological impact of quarantine and how to reduce it: rapid review of the evidence. Lancet. (2020) 395:912-20. doi: 10.1016/S0140-6736(20)30460-8

13. Armitage R, Nellums LB. COVID-19 and the consequences of isolating the elderly. Lancet Public Health. (2020) 5:e256. doi: 10.1016/S2468-2667(20)30061-X

14. Xiao H, Zhang Y, Kong D, Li S, Yang N. Social capital and sleep quality in individuals who self-isolated for 14 days during the coronavirus disease 2019 (COVID-19) outbreak in January 2020 in China. Med Sci Monit. (2020) 26:e923921. doi: 10.12659/MSM.923921

15. Wang C, Pan R, Wan X, Tan Y, Xu L, Ho CS, et al. Immediate psychological responses and associated factors during the initial stage of the 2019 coronavirus disease (COVID-19) epidemic among the

\section{AUTHOR CONTRIBUTIONS}

All authors listed have made a substantial, direct and intellectual contribution to the work, and approved it for publication.

\section{FUNDING}

CM-S was funded by the Erasmus + Program of the European Union: Phoenix JDP on Dynamics of Health and Welfare until July 2020 being currently funded by Fraunhofer Portugal AICOS.

general population in China. Int J Environ Res Public Health. (2020) 17:1729. doi: 10.3390/ijerph17051729

16. Lee SM, Kang WS, Cho AR, Kim T, Park JK. Psychological impact of the 2015 MERS outbreak on hospital workers and quarantined hemodialysis patients. Comp Psychiatry. (2018) 87:123-7. doi: 10.1016/j.comppsych.2018.10.003

17. Mak IWC, Chu CM, Pan PC, Yiu MGC, Chan VL. Long-term psychiatric morbidities among SARS survivors. Gen Hosp Psychiatry. (2009) 31:31826. doi: 10.1016/j.genhosppsych.2009.03.001

18. Hossain M, Sultana A, Purihit N. Mental health outcomes of quarantine and isolation for infection prevention: a systematic umbrella review of the global evidence. Epidemiol Health. (2020) 42:e2020038. doi: 10.21203/rs.3.rs-25647/v1

19. Shah K, Kamrai D, Mekala H, Mann B, Desai K, Patel R. Focus on mental health during the coronavirus (COVID-19) pandemic: applying learnings from the past outbreaks. Cureus. (2020) 12:e7405. doi: 10.7759/cureus.7405

20. Barbisch D, Koenig KL, Shih FY. Is there a case for quarantine? Perspectives from SARS to Ebola. Disaster Med Public Health Prep. (2015) 9:54753. doi: $10.1017 / \mathrm{dmp} .2015 .38$

21. Reger MA, Stanley IH, Joiner TE. Suicide mortality and coronavirus disease 2019-a perfect storm? JAMA Psychiatry. (2020). doi: 10.1001/jamapsychiatry.2020.1060. [Epub ahead of print].

22. Caldas Almeida JM, Xavier M. National Epidemiological Study of Mental Health. Lisbon: Faculdade de Ciências Médicas, Universidade Nova de Lisboa (2013).

23. Dias S, Pedro A, Abrantes A, Gama A, Moniz A, Nunes C, et al. Opinião Social: O que pensam os Portugueses em tempos de Covid-19?, Barómetro COVID-19. Lisbon: Escola Nacional de Saúde Pública-Universidade Nova de Lisboa (2020).

24. Sousa Uva A, Serranheira F. A Saúde Ocupacional e o risco de Covid19, Barómetro Covid-19. Lisbon: Escola Nacional de Saúde PúblicaUniversidade Nova de Lisboa (2020).

25. Duan L, Zhu G. Psychological interventions for people affected by the COVID-19 epidemic. Lancet Psychiatry. (2020) 7:300-2. doi: 10.1016/S2215-0366(20)30073-0

26. Kang L, Li Y, Hu S, Chen M, Yang C, Yang BX, et al. The mental health of medical workers in Wuhan, China dealing with the 2019 novel coronavirus. Lancet Psychiatry. (2020) 7:e14. doi: 10.1016/S2215-0366(20)30047-X

27. Qi J, Xu J, Li B, Huang J, Yang Y, Zhang Z, et al. The evaluation of sleep disturbances for Chinese frontline medical workers under the outbreak of COVID-19. medRxiv. (2020) 2020.03.06.20031278.

28. Tam CW, Pang EP, Lam LC, Chiu HF. Severe acute respiratory syndrome (SARS) in Hong Kong in 2003: stress and psychological impact among frontline healthcare workers. Psychol Med. (2004) 34:1197204. doi: 10.1017/S0033291704002247

29. Goulia P, Mantas C, Dimitroula D, Mantis D, Hyphantis T. General hospital staff worries, perceived sufficiency of information and associated psychological distress during the A/H1N1 influenza pandemic. BMC Infect Dis. (2010) 10:322. doi: 10.1186/1471-2334-10-322

30. Lai J, Ma S, Wang Y, Cai Z, Hu J, Wei N, et al. Factors associated with mental health outcomes among health care workers 
exposed to coronavirus disease 2019. JAMA Netw Open. (2020) 3:e203976. doi: 10.1001/jamanetworkopen.2020.3976

31. Zhu Z, Xu S, Wang H, Liu Z, Wu J, Li G, et al. COVID-19 in Wuhan: immediate psychological impact on 5062 health workers. medRxiv. (2020) 2020.02.20.20025338. doi: 10.1101/2020.02.20.20025338

32. Sprang G, Silman M. Posttraumatic stress disorder in parents and youth after health-related disasters. Disaster Med Public Health Prep. (2013) 7:10510. doi: $10.1017 / \mathrm{dmp} .2013 .22$

33. Taylor MR, Agho KE, Stevens GJ, Raphael B. Factors influencing psychological distress during a disease epidemic: data from Australia's first outbreak of equine influenza. BMC Public Health. (2008) 8:347. doi: 10.1186/1471-2458-8-347

34. Liu X, Kakade M, Fuller CJ, Fan B, Fang Y, Kong J, et al. Depression after exposure to stressful events: lessons learned from the severe acute respiratory syndrome epidemic. Comp Psychiatry. (2012) 53:1523. doi: 10.1016/j.comppsych.2011.02.003

35. Wu P, Fang Y, Guan Z, Fan B, Kong J, Yao Z, et al. The psychological impact of the SARS epidemic on hospital employees in China: exposure, risk perception, and altruistic acceptance of risk. Can J Psychiatry. (2009) 54:302-11. doi: 10.1177/070674370905400504

36. Wu P, Liu X, Fang Y, Fan B, Fuller CJ, Guan Z, et al. Alcohol abuse/dependence symptoms among hospital employees exposed to a SARS outbreak. Alcohol Alcohol. (2008) 43:706-12. doi: 10.1093/alcalc/agn073

37. Bai Y, Lin CC, Lin CY, Chen JY, Chue CM, Chou P. Survey of stress reactions among health care workers involved with the SARS outbreak. Psychiatr Serv. (2004) 55:1055-7. doi: 10.1176/appi.ps.55.9.1055

38. Wind TR, Rijkeboer M, Andersson G, Riper H. The COVID-19 pandemic: the 'black swan' for mental health care and a turning point for e-health. Internet Interv. (2020) 20:100317. doi: 10.1016/j.invent.2020.100317

39. Zhou X, Snoswell CL, Harding LE, Bambling M, Edirippulige S, Bai X, et al. The role of telehealth in reducing the mental health burden from COVID-19. Telemed J E Health. (2020) 26:68. doi: 10.1089/tmj.2020.0068

40. McGrath P, Wozney L, Rathore S, Notarianni M, Schellenberg M. Toolkit for e-Mental Health Implementation. Ottawa, ON: MH Canada Co. (2018).

41. Mohr DC, Riper H, Schueller SM. A solution-focused research approach to achieve an implementable revolution in digital mental health. JAMA Psychiatry. (2018) 75:113-4. doi: 10.1001/jamapsychiatry.2017.3838

42. Riper H, Andersson G, Christensen H, Cuijpers P, Lange A, Eysenbach G. Theme issue on e-mental health: a growing field in internet research. J Med Internet Res. (2010) 12:e74. doi: 10.2196/jmir.1713

43. Gosling SD, Mason W. Internet research in psychology. Annu Rev Psychol. (2015) 66:877-902. doi: 10.1146/annurev-psych-010814-015321

44. Proudfoot J, Klein B, Barak A, Carlbring P, Cuijpers P, Lange $\mathrm{A}$, et al. Establishing guidelines for executing and reporting internet intervention research. Cogn Behav Ther. (2011) 40:82-97. doi: 10.1080/16506073.2011.573807

45. Barak A, Klein B, Proudfoot JG. Defining internet-supported therapeutic interventions. Ann Behav Med. (2009) 38:417. doi: 10.1007/s12160-009-9130-7

46. Mohr DC, Burns MN, Schueller SM, Clarke G, Klinkman M. Behavioral intervention technologies: evidence review and recommendations for future research in mental health. Gen Hosp Psychiatry. (2013) 35:3328. doi: 10.1016/j.genhosppsych.2013.03.008

47. Andersson G. Internet interventions: past, present and future. Internet Interv. (2018) 12:181-8. doi: 10.1016/j.invent.2018.03.008

48. Deane FP, Gonsalvez C, Blackman R, Saffioti D, Andresen R. Issues in the development of e-supervision in professional psychology: a review. Aust Psychol. (2015) 50:241-7. doi: 10.1111/ap.12107

49. Liu S, Yang L, Zhang C, Xiang YT, Liu Z, Hu S, et al. Online mental health services in China during the COVID-19 outbreak. Lancet Psychiatry. (2020) 7:e17-8. doi: 10.1016/S2215-0366(20)30077-8

50. ISPUP, INESC-TEC. Diários de uma Pandemia: Resultados da primeira semana de respostas (23/03/2020-30/03/2020). Oporto: Instituto De Saúde Pública da Universidade Do Porto e Instituto de Engenharia de Sistemas e Computadores Tecnologia e Ciência (2020).

51. CESOP. A vida em quarentena: $14 \%$ dos portugueses passaram duas semanas sem sair de casa. Lisbon: CESOP-Centro de Sondagens da Universidade Católica Portuguesa (2020).
52. OPP. Via Verde de apoio OPP para a Investigação Científica em Saúde Psicológica e Mudança Comportamental. Lisbon: OPP (2020).

53. Holmes EA, O'Connor RC, Perry VH, Tracey I, Wessely S, Arseneault L, et al. Multidisciplinary research priorities for the COVID-19 pandemic: a call for action for mental health science. Lancet Psychiatry. (2020) 7:54760. doi: 10.1016/S2215-0366(20)30168-1

54. Chang BP, Kessler RC, Pincus HA, Nock MK. Digital approaches for mental health in the age of covid-19. BMJ. (2020) 369:m2541. doi: 10.1136/bmj.m2541

55. Crawford A, Serhal E. Digital health equity and COVID-19: the innovation curve cannot reinforce the social gradient of health. J Med Internet Res. (2020) 22:e19361. doi: 10.2196/19361

56. FCT. Iniciativas de estímulo e apoio à investigação COVID-19. Lisbon: FCT (2020).

57. Balcombe L, De Leo D. An integrated blueprint for digital mental health services amidst COVID-19. JMIR Ment Health. (2020) 7:e21718. doi: 10.2196/21718

58. Espinoza J, Crown K, Kulkarni O. A guide to chatbots for COVID-19 screening at pediatric health care facilities. JMIR Public Health Surveill. (2020) 6:e18808. doi: 10.2196/18808

59. Fagherazzi G, Goetzinger C, Rashid MA, Aguayo GA, Huiart L. Digital health strategies to fight COVID-19 worldwide: challenges, recommendations, and a call for papers. J Med Internet Res. (2020) 22:e19284. doi: 10.2196/19284

60. Wang Y. The Chinese Suicides Prevented by AI From AFAR. London: BBC World Service (2019).

61. Torous J, Kiang MV, Lorme J, Onnela J-P. New tools for new research in psychiatry: a scalable and customizable platform to empower data driven smartphone research. JMIR Mental Health. (2016) 3:e16. doi: 10.2196/mental.5165

62. Onnela J-P, Rauch SL. Harnessing smartphone-based digital phenotyping to enhance behavioral and mental health. Neuropsychopharmacology. (2016) 41:1691-6. doi: 10.1038/npp.2016.7

63. Bento H. Covid-19. "Não sofra em silêncio": as várias linhas de apoio psicológico em altura de pandemia (lista em permanente atualização). Lisbon: Público (2020).

64. SNS24. Aconselhamento psicológico no SNS 24. Lisbon: SNS24-Centro de Contacto Serviço Nacional de Saúde (2020).

65. SNS. Linha do Centro de Contacto SNS 24 atendeu já mais de 23 mil chamadas. Lisbon: Serviço Nacional de Saúde (2020).

66. Carvalho R, Fonseca A, Dores A, Santos CM, Batista J, Salgado J, et al. Linhas de Orientação para a Prestação de Serviços de Psicologia Mediados por Tecnologias da Informação e da Comunicação (TIC). In: OPP, editor. Linhas de Orientação para a Prática Profissional. Porto (2019).

67. SNS. Consultas em Telemedicina. Lisbon: Serviço Nacional de Saúde (2020).

68. Mendes-Santos C, Weiderpass E, Santana R, Andersson G. Portuguese psychologists' attitudes toward internet interventions: exploratory crosssectional study. JMIR Ment Health. (2020) 7:e16817. doi: 10.2196/ 16817

69. Ben-Zeev D. The digital mental health genie is out of the bottle. Psychiatr Serv. (2020). doi: 10.1176/appi.ps.202000306. [Epub ahead of print].

70. Lusa. Mais de metade da população mundial está confinada em casa. Paris: SÁBADO (2020).

71. Lavie CJ, Ozemek C, Carbone S, Katzmarzyk PT, Blair SN. Sedentary behavior, exercise, cardiovascular health. Circ Res. (2019) 124:799815. doi: 10.1161/CIRCRESAHA.118.312669

72. Boulos C, Salameh P, Barberger-Gateau P. Social isolation and risk for malnutrition among older people. Geriatr Gerontol Int. (2017) 17:28694. doi: 10.1111/ggi.12711

73. Andersson G, Bergström J, Buhrman M, Carlbring P, Holländare F, Kaldo $\mathrm{V}$, et al. Development of a new approach to guided self-help via the internet: the Swedish experience. J Technol Hum Serv. (2008) 26:16181. doi: 10.1080/15228830802094627

74. Andersson G, Titov N. Advantages and limitations of internet-based interventions for common mental disorders. World Psychiatry. (2014) 13:411. doi: $10.1002 /$ wps. 20083

75. Andersson G, Hesser H, Veilord A, Svedling L, Andersson F, Sleman $\mathrm{O}$, et al. Randomised controlled non-inferiority trial with 3-year follow-up of internet-delivered versus face-to-face group 
cognitive behavioural therapy for depression. J Affect Disord. (2013) 151:986-94. doi: 10.1016/j.jad.2013.08.022

76. Wagner B, Horn AB, Maercker A. Internet-based versus faceto-face cognitive-behavioral intervention for depression: a randomized controlled non-inferiority trial. J Affect Disord. (2014) 154:113-21. doi: 10.1016/j.jad.2013.06.032

77. O'Mahen HA, Richards DA, Woodford J, Wilkinson E, McGinley J, Taylor RS, et al. Netmums: a phase II randomized controlled trial of a guided Internet behavioural activation treatment for postpartum depression. Psychol Med. (2014) 44:1675-89. doi: 10.1017/S0033291713002092

78. Mohr DC, Duffecy J, Ho J, Kwasny M, Cai X, Burns MN, et al. A randomized controlled trial evaluating a manualized TeleCoaching protocol for improving adherence to a web-based intervention for the treatment of depression. PLoS ONE. (2013) 8:e70086. doi: 10.1371/journal.pone.0070086

79. Andersson G, Paxling B, Roch-Norlund P, Ostman G, Norgren A, Almlov $J$, et al. Internet-based psychodynamic versus cognitive behavioral guided self-help for generalized anxiety disorder: a randomized controlled trial. Psychother Psychosom. (2012) 81:344-55. doi: 10.1159/000339371

80. Carlbring P, Maurin L, Törngren C, Linna E, Eriksson T, Sparthan E, et al. Individually-tailored, internet-based treatment for anxiety disorders: a randomized controlled trial. Behav Res Ther. (2011) 49:1824. doi: 10.1016/j.brat.2010.10.002

81. Paxling B, Almlov J, Dahlin M, Carlbring P, Breitholtz E, Eriksson T, et al. Guided internet-delivered cognitive behavior therapy for generalized anxiety disorder: a randomized controlled trial. Cogn Behav Ther. (2011) 40:15973. doi: $10.1080 / 16506073.2011 .576699$

82. Hedman E, Ljótsson B, Rück C, Bergström J, Andersson G, Kaldo V, et al. Effectiveness of internet-based cognitive behaviour therapy for panic disorder in routine psychiatric care. Acta Psychiatr Scand. (2013) 128:45767. doi: $10.1111 /$ acps. 12079

83. Spence J, Titov N, Dear BF, Johnston L, Solley K, Lorian C, et al. Randomized controlled trial of internet-delivered cognitive behavioral therapy for posttraumatic stress disorder. Depress Anxiety. (2011) 28:54150. doi: $10.1002 /$ da. 20835

84. Blom K, Tarkian Tillgren H, Wiklund T, Danlycke E, Forssen M, Soderstrom $A$, et al. Internet-vs. group-delivered cognitive behavior therapy for insomnia: a randomized controlled non-inferiority trial. Behav Res Ther. (2015) 70:47-55. doi: 10.1016/j.brat.2015.05.002

85. Ivarsson D, Blom M, Hesser H, Carlbring P, Enderby P, Nordberg R, et al. Guided internet-delivered cognitive behavior therapy for post-traumatic stress disorder: a randomized controlled trial. Internet Interv. (2014) 1:3340. doi: 10.1016/j.invent.2014.03.002

86. Buhrman M, Faltenhag S, Strom L, Andersson G. Controlled trial of Internetbased treatment with telephone support for chronic back pain. Pain. (2004) 111:368-77. doi: 10.1016/j.pain.2004.07.021

87. Andersson G, Stromgren T, Strom L, Lyttkens L. Randomized controlled trial of internet-based cognitive behavior therapy for distress associated with tinnitus. Psychosom Med. (2002) 64:810-6. doi: 10.1097/00006842-200209000-00014

88. Ljótsson B, Andersson G, Andersson E, Hedman E, Lindfors P, Andréewitch $\mathrm{S}$, et al. Acceptability, effectiveness, and cost-effectiveness of internetbased exposure treatment for irritable bowel syndrome in a clinical sample: a randomized controlled trial. BMC Gastroenterology. (2011) 11:110. doi: 10.1186/1471-230X-11-110

89. Kitsiou S, Paré G, Jaana M, Gerber B. Effectiveness of mHealth interventions for patients with diabetes: an overview of systematic reviews. PLoS ONE. (2017) 12:e0173160. doi: 10.1371/journal.pone.0173160

90. Hadjiconstantinou M, Byrne J, Bodicoat DH, Robertson N, Eborall H, Khunti K, et al. Do web-based interventions improve well-being in type 2 diabetes? A systematic review and meta-analysis. J Med Internet Res. (2016) 18:e270. doi: 10.2196/jmir.5991

91. Agboola SO, Ju W, Elfiky A, Kvedar JC, Jethwani K. The effect of technologybased interventions on pain, depression, and quality of life in patients with cancer: a systematic review of randomized controlled trials. J Med Internet Res. (2015) 17:e65. doi: 10.2196/jmir.4009

92. Kuijpers W, Groen WG, Aaronson NK, van Harten WH. A systematic review of web-based interventions for patient empowerment and physical activity in chronic diseases: relevance for cancer survivors. J Med Internet Res. (2013) 15:e37. doi: 10.2196/jmir.2281
93. McAlpine H, Joubert L, Martin-Sanchez F, Merolli M, Drummond KJ. A systematic review of types and efficacy of online interventions for cancer patients. Patient Educ Counsel. (2015) 98:283-95. doi: 10.1016/j.pec.2014.11.002

94. Kim AR, Park HA. Web-based self-management support interventions for cancer survivors: a systematic review and meta-analyses. Stud Health Technol Inform. (2015) 216:142-7. doi: 10.3233/978-1-61499-564-7-142

95. Wang H, Zhang L. Risk of COVID-19 for patients with cancer. Lancet Oncol. (2020) 21:e181. doi: 10.1016/S1470-2045(20)30149-2

96. Mendes-Santos C, Weiderpass E, Santana R, Andersson G. A guided internet-delivered individually-tailored ACT-influenced cognitive behavioural intervention to improve psychosocial outcomes in breast cancer survivors (iNNOVBC): study protocol. Internet Interv. (2019) 17:100236. doi: 10.1016/j.invent.2019.01.004

97. Fonseca A, Pereira M, Araújo-Pedrosa A, Gorayeb R, Ramos MM, Canavarro MC. Be a mom: formative evaluation of a web-based psychological intervention to prevent postpartum depression. Cogn Behav Pract. (2018) 25:473-95. doi: 10.1016/j.cbpra.2018.02.002

98. Sousa M, Barbosa E, Meira L, Silva S, Basto I, Pinheiro P, et al. Clinical results of the pilot study of the iCare4Depression project. In: 35th Annual Conference of the Society for the Exploration of Psychotherapy Integration, Lisbon (2019).

99. Salgado J, Ferreira T, Rocha A, Meira L, Cunha C, Santos A, et al. Stop depression: Implementando y evaluando un modelo de stepped care para el tratamiento de la depresión. In: IX Congreso Internacional y XIV Nacional de Psicología Clínica, Santander (2016).

100. FCT. Research4COVID-19 Call. Lisbon: Fundação para a Ciência e a Tecnologia (2020).

101. Salgado J, Gomes P. Webinar OPP: Consultas de Psicologia à distância (Um guia breve para resposta à crise COVID-19). Lisbon: Ordem dos Psicólogos Portugueses (2020).

102. Torous J, Jän Myrick K, Rauseo-Ricupero N, Firth J. Digital mental health and COVID-19: using technology today to accelerate the curve on access and quality tomorrow. JMIR Ment Health. (2020) 7:e18848. doi: 10.2196/18848

103. SPMS. Plano Estratégico Nacional para a Telesaúde 2019-2022. Lisbon: Serviços Partilhados do Ministério da Saúde (2019).

104. Barak A, Hen L, Boniel-Nissim M, Shapira Na. A comprehensive review and a meta-analysis of the effectiveness of internet-based psychotherapeutic interventions. J Technol Hum Serv. (2008) 26:109-60. doi: 10.1080/15228830802094429

105. Richards D, Richardson T. Computer-based psychological treatments for depression: a systematic review and meta-analysis. Clin Psychol Rev. (2012) 32:329-42. doi: 10.1016/j.cpr.2012.02.004

106. Andersson G, Cuijpers P. Internet-based and other computerized psychological treatments for adult depression: a meta-analysis. Cogn Behav Ther. (2009) 38:196-205. doi: 10.1080/16506070903318960

107. Berryhill MB, Culmer N, Williams N, Halli-Tierney A, Betancourt A, Roberts $\mathrm{H}$, et al. Videoconferencing psychotherapy and depression: a systematic review. Telemed J E Health. (2019) 25:435-46. doi: 10.1089/tmj.2018.0058

108. PNSM. Programa Nacional para a Saúde Mental 2017. Lisbon: Direção-Geral da Saúde, Ministério da Saúde (2017).

Disclaimer: The authors alone are responsible for the views expressed in this article, and they do not necessarily represent the decisions, policy, or views of the International Agency for Research on Cancer/World Health Organization, Linköping University, NOVA National School of Public Health, Fraunhofer Portugal AICOS, or Karolinska Institutet.

Conflict of Interest: The authors declare that the research was conducted in the absence of any commercial or financial relationships that could be construed as a potential conflict of interest.

Copyright $\odot 2020$ Mendes-Santos, Andersson, Weiderpass and Santana. This is an open-access article distributed under the terms of the Creative Commons Attribution License (CC BY). The use, distribution or reproduction in other forums is permitted, provided the original author(s) and the copyright owner $(s)$ are credited and that the original publication in this journal is cited, in accordance with accepted academic practice. No use, distribution or reproduction is permitted which does not comply with these terms. 